\title{
USG in evaluation of patients with scrotal pain
}

\author{
P.K Chhetri ${ }^{1}$, A. Tayal ${ }^{2}$, P. K. Deka ${ }^{3}$ \\ ${ }^{1}$ Assistant Professor, ${ }^{2}$ Associate Professor, ${ }^{3}$ Professor \& HOD \\ Department of Radiodiagnosis, College of Medical Sciences- Teaching Hospital, Bharatpur, Chitwan, Nepal
}

\begin{abstract}
Based on physical examination alone it is often difficult to accurately make a clinical diagnosis and decide whether a palpable scrotal pathology arises from the testis itself or from extratesticular elements within the scrotum. Clinical examination of the testis is especially difficult due to pain, tenderness or when obscured by a large hydrocele. The aim of the study was thus undertaken to evaluate the role of ultrasonography (USG) in patients presenting with scrotal pain. 50 patients who presented to the surgical department with scrotal pain were subjected to USG. The commonest cause for scrotal pain was epididymitis with or without orchitis (40\%), followed in descending order by cystic lesions of the epididymis (18\%), varicocele (12\%), trauma (8\%), torsion (4\%) and tumour $(2 \%)$. No abnormality was seen on USG in 7 patients ( $14 \%$ ). This study concludes that USG is a sensitive and specific examination in patients with scrotal pain. Besides differentiating testicular from extratesticular origin it can also differentiate solid from cystic masses. Colour flow imaging is especially helpful in varicocele and testicular torsion. Torsion of the testis remains the most urgent and important entity dependent on USG for diagnosis.
\end{abstract}

Key words: Scrotal pain, USG.

\section{Introduction}

Diagnostic ultrasound is the most common imaging technique used to supplement the physical examination of the scrotum and is an accurate means of evaluating many scrotal diseases. With USG examination, intrascrotal masses can be detected with a sensitivity of almost $100 \% .{ }^{1}$ USG is important in the evaluation of scrotal masses because its accuracy is $98 \%$ to $100 \%$ in distinguishing intratesticular from extratesticular pathology. ${ }^{2}$ This distinction is important in disease management because most extratesticular masses are benign, but the majority of intratesticular lesions are malignant. $^{3}$

Correspondence: P.K Chhetri

E-mail:pramodchhetri@rediffmail.com
While CT and MRI have dominated imaging of many regions of the body they both have limitation in scrotal pathology. CT has the major drawback of radiation and MRI its cost. USG is exceptionally well suited to the study of the scrotum. It is simple to perform, rapid, non- invasive, inexpensive, safe and reproducible.

Miskin M and Bain J ${ }^{4}$ in 1974 were the first to perform USG examination of the scrotum using B mode static scanner with a $2.5 \mathrm{MHz}$ transducer. In 1976, Miskin M, Buckspan M and Bain J ${ }^{5}$ presented details of Bmode as well as grey scale images with a high frequency $5 \mathrm{MHz}$ transducer. 
P.K Chhetri, USG in evaluation of patients with scrotal pain Technical advancements in high resolution real-time and color flow Doppler USG have led to an increase in the clinical applications of scrotal USG.

\section{Materials and methods}

This study was undertaken in the Department of Radiodiagnosis, College of Medical Sciences Teaching Hospital during one period from 2010 to 2011. All patients with scrotal pain were referred for USG after clinical examination by the surgeon. The patient was examined in the supine position. The scrotum was elevated with a towel draped over the thighs, and the penis placed on the patient's abdomen and covered with a towel. Ahigh-frequency $(7.5 \mathrm{MHz})$ linear array transducer of Toshiba Xario USG machine was used in this study. Images of both testes were obtained in transverse and sagittal planes. Additional views were obtained in the coronal or oblique planes, with the patient upright or performing the Valsalva maneuver when necessary. Color flow and power mode Doppler USG were also performed to evaluate testicular blood flow in normal and pathologic states.

Subsequently these cases were followed and correlated with fine needle aspiration cytology or histopathology reports, surgical findings and response to treatment. Follow up scan were done when indicated. All patients lost for follow up after initial USG were excluded from the study.

\section{Observation}

50 patients presenting with scrotal pain were subjected for USG examination from the surgery department and followed up thereafter with either medical or surgical treatment as advised by the attending surgeon.
The age distribution of the 50 patients is shown in Table 1. As noted in the table, most of the patients were 2040 years of age accounting for $45(90 \%)$ of the 50 patients. The highest number of cases was in the 2030 years $(50 \%)$.

Table 1: Age distribution of patient presenting with scrotal pain

\begin{tabular}{ccc}
\hline Age of patients & No of cases & \% \\
\hline $21-30$ & 25 & 50 \\
$31-40$ & 20 & 40 \\
$41-50$ & 3 & 6 \\
$51-60$ & 2 & 4 \\
Total & $\mathbf{5 0}$ & $\mathbf{1 0 0}$ \\
\hline
\end{tabular}

Most of the patients had unilateral scrotal pain (85\%). The left testis was slight more affected than the right (56\% versus $44 \%$ ).

Table 2: USG findings in the patients presenting with scrotal pain.

\begin{tabular}{lcc}
\hline $\begin{array}{l}\text { USG } \\
\text { findings }\end{array}$ & $\begin{array}{c}\text { No of patients } \\
(\mathbf{n = 5 0})\end{array}$ & \% \\
\hline Epididymitis (acute/chronic) & 15 & 30 \\
Epididymo-orchitis & 5 & 10 \\
Cystic lesions of the epididymis & 9 & 18 \\
Normal scan & 7 & 14 \\
Varicocele & 6 & 12 \\
Trauma & 4 & 8 \\
Torsion & 2 & 4 \\
Malignancy & 1 & 2 \\
\hline
\end{tabular}

As noted in Table 2 inflammatory lesions accounted for the majority of the cases. Epididymitis with or without orchitis were seen in 20 patients (40\%). Cystic 
lesions of the epididymis were the next most common cause (18\%). Normal scan was seen in 7 cases (14 $\%)$. USG confidently diagnosed testicular torsion in 2 cases $(4 \%)$. Malignancy as a cause of scrotal pain was seen in only one patient ( $2 \%)$.

Seven $(14 \%)$ of the patient had no abnormality detected on USG. These patients had only mild testicular discomfort. They were treated symptomatically. None of the patients returned to the hospital with similar pain.

\section{Discussion}

The superficial location of the scrotum along with the advent of high resolution USG makes it the initial investigation of choice in patients with scrotal pain. Most of the lesions could confidently be diagnosed on USG alone.

In this present study, the majority of the pathology diagnosed on USG was inflammatory accounting for 20 of the 50 patients ( $40 \%$ ) with non-inflammatory lesions accounting for $23(46 \%)$. Normal scan was seen in 7 cases (14\%). Arger PH et al ${ }^{6}$ in a series of 62 patients detected inflammatory disease in 16 cases (26\%) and non-inflammatory disease in 45 cases ( 72 $\%$ ). Richie JP et al ${ }^{7}$ in their study of 124 patients on USG found inflammatory lesions in $31(25 \%)$ and non -inflammatory lesions in 75 cases $(60 \%)$. Though inflammatory lesions accounted for the highest single number of cases the vast majority of the lesions were non-inflammatory.

The USG features of epididymitis is characteristic, the epididymis may be involved in focal areas (often the lower is affected first) or in a global pattern, with enlargement, decreased reflectivity and increased
Colour Doppler flow. ${ }^{8,9}$ The increased Colour Doppler flow to the inflamed epididymis is the mark for hyperemia and conveniently aids the diagnosis of epididymitis. There is often a reactive hydrocele. The infection may spread to the adjacent testis (epididymoorchitis), seen as patchy areas of low reflectivity and increased Colour Doppler signal, an appearance that may persist for several months following treatment.$^{10}$

Epididymal cysts are most commonly found in the epididymal head, contain clear serous fluid and on USG demonstrate features typical of a cyst; anechoic structure with posterior acoustic enhancement. A spermatocele consists of cystic dilatation of tubules of efferent ductules and occurs in the epididymal head, often containing low reflective debris representing spermatozoa, lymphocytes, cellular debris fat and proteinaceous fluid. ${ }^{11}$ The differentiation between a spermatocele and a simple cyst is unimportant and often indistinguishable on USG. A spermatocele is more common than an epididymal cyst and more frequent in the epididymal head.

A varicocele was considered to be present on high frequency USG if 2 or more veins could be identified with at least 1 vein having greater diameter of $3 \mathrm{~mm}$ or greater. A varicocele was considered to be present by color Doppler USG if retrograde flow was identified within the pampiniform plexus spontaneously and / or during Valsalva maneuver. ${ }^{12}$ All the varicoceles were seen on the left side in the present study. The left-sided predominance probably occurs because the venous drainage on the left side is into the renal vein, as opposed to the right spermatic vein, which drains directly into the vena cava.

A prior history of trauma with the findings of hematocele with or without intra-testicular hematomas as evidenced by either hyper or hypoechoic changes 
P.K Chhetri, USG in evaluation of patients with scrotal pain without flow on Doppler is often diagnostic. Acutely the hematoma appears as increased reflectivity that becomes low reflective and decreases in size as the hematoma retracts, to eventually resolve completely.

Two cases with acute testicular torsion were diagnosed and later confirmed on surgery with findings of enlarged unilateral testis and decreased vascularity on Doppler USG. Prompt diagnosis is necessary because torsion requires immediate surgery to preserve the testis. The testicular salvage rate is $80 \%$ to $100 \%$ if surgery is performed within 5 to 6 hours of the onset of pain, $70 \%$ if surgery is performed within 6 to 12 hours, and only $20 \%$ if surgery is delayed for more than 12 hours. 13

Color Doppler USG is the most useful and most rapid technique to establish the diagnosis of testicular torsion and to help distinguish torsion from epididymo-orchitis. In torsion, blood flow is absent in the affected testicle or significantly less than in the normal, contralateral testis. ${ }^{14,15}$

A diagnosis of testicular malignancy was made in a single patient with a heterogenous mass within the testis distorting the testicular contour and having solid \& cystic component with calcifications. USG abdomen also showed enlarged retroperitoneal nodes. FNAC showed a germ cell tumor.

\section{Conclusion}

1. USG with Color Doppler is a sensitive and specific imaging modality in the diagnostic work up of patients with scrotal pain. It is useful for differentiating solid form cystic mass and testicular from extratesticular masses.
2. Epididymitis is the most common cause of scrotal pain. Torsion of the testis remains the most urgent and important entity dependent on USG for diagnosis.

\section{References}

1. Brian Gorma. The Scrotum. C.M. Rumack, S.R. Wilson, J.W. Charboneau et al. Diagnostic Ultrasound. 4 th edi. Philadelphia: Mosby Elsevier;2011:840-77.

2. M.D. Rifkin, A.B. Kurtz, M.E. Pasto et al. Diagnostic capabilities of high-resolution scrotal ultrasonography: prospective evaluation. J Ultrasound Med 1985;4:139.

3. B.A. Carroll D.M. Gross. High-frequency scrotal sonography. AJR Am J Roentgenol 1983;140:511-5.

4. Murray Miskin and Jerald Bain. B- mode ultrasonic examination of the testes. Journal of Clinical Ultrasound, 1974;2:307.

5. Murray Miskin, Martin Buckspan and Jerald Bain. Ultrasound examination of scrotal masses. The Journal of Urology, 1997;117:185-8.

6. P.H. Arger, C.B. Jr. Mulhern, B.G. Coleman et al. Prospective analysis of the value of scrotal ultrasound. Radiology 181;141:763-6.

7. J.P. Richie, J.Birnholz, M.B. Garnick. Ultrasonography as a diagnostic adjunct for the evaluation of masses in the scrotum. Surgery-Gynecology-Obstetric, 1982; 154:695-8.

8. W.G. Horstman, W.D. Middleton, G.L. Melson. Scrotal inflammatory disease: Color Doppler US findings. Radiology 1991;179:55-9. 
Journal of College of Medical Sciences-Nepal, 2012, Vol-8, No-1

9. S.W. Fitzgerald, S.J. Erickson, D.M. Dewire et al. Color sonography in the evaluation of the adult acute scrotum. J Ultrasound Med 1992;11:543-8.

10. J.L. Cook, K. Dewbury. The changes seen on highresolution ultrasound in orchitis. Clin Radiol 2000;55:13-8

11. M.D. Rifkin, A.B. Kurtz B.B. Goldberg. Epididymis examined by ultrasound: correlation with pathology. Radiology 1984;151:187-90.

12. R. B. Meachan. The incidence of varicocele in the general population when evaluated by physical examination, gray scale sonography and Color Doppler sonography. The Journal of Urology, 1994:151:1535-8.

13. H. Hricak, T. Lue, R.A. Filly. et al. Experimental study of the sonographic diagnosis of testicular torsion. $J$ Ultrasound Med 1983;2:349-56.

14. D.L. Mueller, G.M. Amundson, S.Z. Rubin. et al. Acute scrotal abnormalities in children: diagnosis by combined sonography and scintigraphy. AJR Am J Roentgenol 1988;150:643-6.

15. W.D. Middleton, G.L. Melson. Testicular ischemia: color Doppler sonographic findings in five patients. AJR Am J Roentgenol 1989;152:1237-9. 